\title{
Meta-hierarchical-heuristic-mathematical- model of loading problems in flexible manufacturing system for development of an intelligent approach
}

\author{
Ranbir Singh ${ }^{\mathrm{a}^{*}}$, Rajender Singh ${ }^{\mathrm{b}}$ and B.K. Khan ${ }^{\mathrm{c}}$
}

${ }^{a}$ Research Scholar, Deptt. of Mech. Engg., DCRUST Murthal, Sonipat (Haryana), 131039, India

${ }^{b}$ Professor, Deptt. of Mech. Engg., DCRUST Murthal, Sonipat (Haryana), 131039, India

${ }^{\circ}$ Director, MSIT Jagdishpur, Sonipat (Haryana), India

\section{H R O N I C L E}

\section{Article history:}

Received July 222015

Received in Revised Format

Septmber 172015

Accepted November 152015

Available online

November 152015

Keywords:

Flexible manufacturing system

(FMS)

Loading in FMS

Realistic modelling

Mathematical modelling of FMS

Artificial intelligence in FMS

\begin{abstract}
A B S T R A C T
Flexible manufacturing system (FMS) promises a wide range of manufacturing benefits in terms of flexibility and productivity. These benefits are targeted by efficient production planning. Part type selection, machine grouping, deciding production ratio, resource allocation and machine loading are five identified production planning problems. Machine loading is the most identified complex problem solved with aid of computers. System up gradation and newer technology adoption are the primary needs of efficient FMS generating new scopes of research in the field. The literature review is carried and the critical analysis is being executed in the present work. This paper presents the outcomes of the mathematical modelling techniques for loading of machines in FMS's. It was also analysed that the mathematical modelling is necessary for accurate and reliable analysis for practical applications. However, excessive computations need to be avoided and heuristics have to be used for real-world problems. This paper presents the heuristics-mathematical modelling of loading problem with machine processing time as primary input. The aim of the present work is to solve a real-world machine loading problem with an objective of balancing the workload of the FMS with decreased computational time. A Matlab code is developed for the solution and the results are found most accurate and reliable as presented in the paper.
\end{abstract}

\section{Introduction}

Flexible Manufacturing System in 1960's has evolved with the composition of machines with different capability and capacity constraints. Installation of flexible manufacturing system can be increased through research with physical significance and practical approach \& acceptance. In coming decades, the diversity has reduced to negligible amount with technological improvements and advances with the development of advanced CNC's, tool changers, tool transportation systems, automatic material handling system, developments in computer technologies etc. The acceptance and installation of FMS is much lower than expected because of higher installation, running and maintenance cost. FMS is the most * Corresponding author. Tel: +91-9813043366 E-mail: ranbirsheoran@gmail.com (R. Singh) 
accepted manufacturing strategy in the Computer Integrated Manufacturing system. The FMS is composed of a large number of CNC's, with automatic material handling systems, automatic storage and retrieval system, robots, automatic tool changers, tool transporters, which involve a higher installation and running cost. Thus the cost of installation and operating a FMS needs to be initially identified and approved. Production planning is the pilot element in estimating manufacturing cost which is the ever ending research element for any strategy. As the objectives of production planning varies, which requires optimization ideas to implement for different cost reduction manufacturing functions, the need of research arises.

There are a large number of production planning objectives, and different types of manufacturing industries require single or combination of different production planning objectives. Along with the large number of different production planning objectives there are various kinds of objectives. Thus the problem pertaining to multi-production planning objectives coupled with evaluation of multi optimization objectives needs to be investigated. One of the production planning problems is the loading of machines. The elements of loading are the jobs, machines, tools and operations under constraints to achieve some objectives. Manufacturing has different operational requirements; the operations can be performed on different machines using various tools in different times. The same operation can be performed in different times on same machine with various tools, and also in different times on different machines, and there are some capacity and technical constraints and some objectives. Hence as the number of elements, constraints and objectives increases, the complexity of the problem increases too. There are three types of grouping in FMS yielding three various kinds of environments for the loading problem in an FMS, i.e., no grouping, partial grouping, and total grouping (Lee \& Kim, 2000).

To increase the acceptability of FMS, the group technology requirement of FMS needs to be modified from no grouping to full grouping as per the requirement of the manufacturing industry for their survival in today's global customer driven market. Also the multi-vendor concept has also evolved in the market, which has changed the concept of FMS from a group of machines to a group of systems. The small scale industries (SSI) and medium scale industries (MSI) these days are striving for their existence. The major factor is the lack of manufacturing strategy in SSI and MSI. Manufacturing strategy is responsible for the life, health and growth of the firm. The stronger is the manufacturing strategy of the firm, the more is its stability in market, the higher the level of its growth. A manufacturing industry survival in the market depends mainly on the manufacturing strategy. The strategy requirement of SSI and MSI is the flexibility requirement of job shop production and productivity of line layout for multi vendor solution for their survival and growth. To optimally utilize the machines and tools the production planning needs to be carried out prior to scheduling, i.e. loading of machines. The present work focuses on the development of Hybrid-Hierarchical-Heuristic-Mathematical-Model of Loading Problems in Flexible Manufacturing System for Throughput Optimization for loading of machines in FMS.

\section{The literature review}

A model is a representation of the construction and working of some system of interest which is similar to but simpler than the system it represents. It enables the analyst to predict the effect of changes to the system. The beauty of any model lies in its close approximation to the real system, incorporation of its salient features and minimum complexity. An important issue in modelling is model validity. According to Maria model validation techniques include simulating the model under known input conditions and comparing model output with system output (Maria, 1997). Mathematics, heuristics, queuing theory etc. have been utilized for modelling various types of complex problems of FMS's. Different modelling methods and approaches utilized by earlier researchers for modelling FMS's, particularly the loading problem of FMS's have been identified, analyzed, classified and presented them in tabular form. Table 1 is review of literature on mathematical modelling of loading problem of FMS. 
Table 1

Mathematical modelling of loading problem of FMS (i) Mixed Integer Programming (MIP)

\begin{tabular}{|c|c|c|}
\hline Author & Loading objectives & Results \\
\hline Stecke (1981) & $\begin{array}{l}\text { Balance assigned machine processing time, maximize number of consecutive } \\
\text { operations on each machine and sum of operation priorities }\end{array}$ & $\begin{array}{l}\text { Linearization methods are suggested } \\
\text { Results are applicable for a particular range of problems }\end{array}$ \\
\hline Stecke (1983b) & Grouping and loading & Need to decrease computational time \\
\hline Ammons et al. (1985) & General loading problem for discrete optimization & Heuristics improves computational efficiency \& effectiveness \\
\hline Berrada \& Stecke (1986) & Minimize machines workload & Heuristics gives efficient solution \\
\hline Wilson ( 1992) & Balancing of workload & $\begin{array}{l}\text { Used approximate solution technique } \\
\text { linearization is necessary }\end{array}$ \\
\hline Taboun \& Ulger (1992) & Minimize cost & Computational requirements for large size problems are impractical \\
\hline Stecke \& Brian (1995) & Optimize real-time solution of loading problems & $\begin{array}{l}\text { Requirement of real-time FMS control } \\
\text { Impractical computational time and cost requirements for nonlinear MIPs } \\
\text { Optimal solution is cost inefficient in real }\end{array}$ \\
\hline Lee et al. (1997) & Minimize subcontracting costs & $\begin{array}{l}\text { Iterative algorithms were developed } \\
\text { Research on such problems is needed to develop planning software that can be } \\
\text { actually implemented in real systems }\end{array}$ \\
\hline Lee \& Kim (1998) & Minimize earliness, tardiness costs and subcontracting costs & $\begin{array}{l}\text { Iterative procedures were developed } \\
\text { Computer generated test results }\end{array}$ \\
\hline $\begin{array}{l}\text { Dobson \& Nambimadom } \\
\text { (2001) }\end{array}$ & Minimize scheduling cost & Heuristics provides more optimal solution \\
\hline Swarnkar \& Tiwari (2004) & Minimize system unbalance and maximize throughput & $\begin{array}{l}\text { Proposed tabu search and simulated } \\
\text { annealing-based hybrid heuristic approach } \\
\text { Exhaustive computations were required }\end{array}$ \\
\hline Sujono \& Lashkari (2007) & Minimize manufacturing cost and maximize compatibility & Validated by numerical example \\
\hline $\begin{array}{l}\text { Jahromi \& Tavakkoli } \\
\text { (2012) }\end{array}$ & Minimize production cost & heuristic method is proposed \\
\hline Kim et al. (2012) & Balancing of workloads $\quad$ (ii) Integer Programming (IP) & Suggested two-stage heuristics \\
\hline Stecke (1983a) & Maximize throughput and machine utilizations & Future need to develop efficient heuristic algorithms for more real life solution \\
\hline Stecke (1986) & Optimal allocation ratios & Developed queueing network model where information is suppressed \\
\hline Greene \& Sadowski (1986) & Minimize make span, flow time and lateness & Identified variables and constraints necessary to solve real world program \\
\hline Sarin \& Chen (1987) & Minimize machining cost & Lagrangian relaxation is proposed \\
\hline Ventura et al. (1988) & Minimize make-span & Heuristic algorithms are proposed \\
\hline Henery et al. (1990) & Balancing of workload and maximize flexibility & Mathematical solution was found impractical \\
\hline Rajamani \& Adil (1996) & Routeing flexibility & Routing flexibility is required for rigid loading schedules \\
\hline Nayak \& Acharya (1998) & Minimize number of batches & heuristic has been proposed \\
\hline $\begin{array}{l}\text { Ozdamarl \& Barbarosoglu } \\
\text { (1999) }\end{array}$ & Minimize the holding cost & GA-SA hybrid heuristics were developed \\
\hline Lee \& Kim (2000) & Minimize maximum workload & Better performance with partial grouping than total grouping, solved by heuristics \\
\hline Kumar \& Shanker (2000) & Genetic algorithms for constrained optimization & GA shows near-optimum performance and need of modern heuristic techniques \\
\hline Kumar \& Shanker (2001) & Balancing of workloads & Results are in agreement with previous findings \\
\hline Yang \& Wu (2002) & Balancing of workloads & Tested for small size test problems only \\
\hline Gamila \& Motavalli (2003) & Minimize total processing time & Used computer generated data for validation \\
\hline Tadeusz (2004) & Minimize inter-station transfer time & Very high computational effort is required for realistic problems \\
\hline Chan et al. (2004) & Minimize system unbalance and maximize throughput & $\begin{array}{l}\text { Validated only for small set of test problems } \\
\text { Require further extension of research }\end{array}$ \\
\hline Chen \& Ho (2005) & Minimize flow time \& tool cost and workload unbalancing & multi-objective genetic algorithm $(\mathrm{GA})$ is proposed \\
\hline Bilgin \& Azizoglu (2006) & Optimization of total processing time & near-optimal solution in reasonable time \\
\hline Nagarjuna et al. (2006) & Minimize system unbalance & $\begin{array}{l}\text { Proposed heuristic yields good results } \\
\text { Further extension of work is required }\end{array}$ \\
\hline Goswami \& Tiwari (2006) & Minimize system unbalance and maximize throughput & Performed extensive computational experiments \\
\hline Kumar et al. (2006) & Minimize system unbalance and maximize throughput & $\begin{array}{l}\text { Proposed constraint-based genetic algorithm } \\
\text { comprehensive } \\
\text { exploration of research is required }\end{array}$ \\
\hline Turkcan et al. (2007) & Minimize tardiness and manufacturing cost & Used sequential and simultaneous approaches for solution \\
\hline Biswas \& Mahapatra (2007) & Minimize system unbalance & need to consider more realistic variables and constraints \\
\hline Biswas \& Mahapatra (2008) & $\begin{array}{l}\text { Minimize system unbalance with improved solution quality and reduced computational } \\
\text { effort }\end{array}$ & $\begin{array}{l}\text { Proposed particle swarm optimization based meta-heuristic approach } \\
\text { Future study to solve the loading problem for multiple-objective framework is } \\
\text { required }\end{array}$ \\
\hline $\begin{array}{l}\text { Ponnambalam \& Kiat } \\
\text { (2008) } \\
\text { Yogeswaran et al. (2009) }\end{array}$ & Bi-criterion objective to minimize system unbalance and maximize throughput & $\begin{array}{l}\text { Used Particle Swarm Optimization } \\
\text { Need of further optimization } \\
\text { GA-SA hybrid algorithms were proposed }\end{array}$ \\
\hline $\begin{array}{l}\text { Ozpeynirci \& Azizoglu } \\
\text { (2010) }\end{array}$ & Maximize total weight of the assigned operations minus total tooling cost & Used Lagrangian relaxation approach for near optimal results \\
\hline Mandal et al. (2010) & Maximise throughput and minimize system unbalance \& make-span & $\begin{array}{l}\text { Need to solve the problem in a more realistic environment with more objectives } \\
\text { Felt the need of new solution methodology }\end{array}$ \\
\hline Yusof et al. (2011) & Balancing of productivity and flexibility & $\begin{array}{l}\text { Proposed harmony search algorithm Optimization based methods tend to become } \\
\text { impractical with the increase in problem size }\end{array}$ \\
\hline Mgwatu (Mgwatu, 2011) & Machining optimisation and part scheduling sub-problems & two-stage sequential methodology was adopted \\
\hline Yusof et al. (2011) & Minimize system unbalance and increase throughput & $\begin{array}{l}\text { Proposed hybrid GA-Harmony Search algorithm } \\
\text { Need to solve multi-objective real life large scale machine loading problems }\end{array}$ \\
\hline Murat \& Erol (2012) & Minimize system unbalance & Proposed hybrid simulated annealing-tabu search algorithm \\
\hline Yusof et al. (2012) & Minimize system unbalance and maximize throughput & $\begin{array}{l}\text { Proposed constraint-chromosome genetic algorithm and identified the need to } \\
\text { solve the problem for solve multi-objectives }\end{array}$ \\
\hline Kumar et al. (2012) & Minimize system unbalance and maximize throughput simultaneously & Proposed GA-PSO based meta-hybrid heuristic technique \\
\hline $\begin{array}{l}\text { Yaqoub \& Abdulghafour } \\
\text { (2012) }\end{array}$ & Meeting delivery dates and reducing manufacturing cost & Need of further research for cost oriented analysis \\
\hline Abazari et al. (2012) & Maximize profitability and utilization of system & $\begin{array}{l}\text { Evaluated unconstrained results by mathematical programming model } \\
\text { Felt the need to solve the problem optimally }\end{array}$ \\
\hline Mahmudy et al. (2012) & $\begin{array}{l}\text { Maximize throughput and } \\
\text { balancing of system }\end{array}$ & $\begin{array}{l}\text { Proposed real coded genetic algorithms } \\
\text { Stated the requirement of more powerful GA }\end{array}$ \\
\hline Kosucuoglu \& Bilge (2012) & Minimize total distance travelled by parts & Need of research for multi-objective meta-heuristic solution \\
\hline \multicolumn{3}{|c|}{ (iii) Integer constraint } \\
\hline Kouvelis \& Lee (1991) & Minimizae operating cost & Jeed to avoided non-linearity to reduce computational time \\
\hline \multicolumn{3}{|c|}{ (iv) Goal Programming (GP) } \\
\hline Kumar et. al. (1991) & Grouping & $\begin{array}{l}\text { Sequential search algorithms were developed } \\
\text { Solution obtained by box-complex method }\end{array}$ \\
\hline $\begin{array}{l}\text { Atmaca \& Erol (Atmaca \& } \\
\text { Erol, 2000) }\end{array}$ & Maximize throughput, workload balancing and minimize material handling & Tested for small problems \\
\hline
\end{tabular}

The loading problems of FMS were observed to be modelled with Mathematical Modelling during the period of 1981-2012. Most of the developed mathematical model are not suitable to solve large problems (Nayak \& Acharya, 1998). Taboun and Ulger (1992) concluded that computational requirements of 
mathematical model for large size problems can be impractical (Taboun \& Ulger, 1992). Wilson (1992) outlined that linearization is necessary (Wilson, 1992) for near real and optimal results. Further Table 2 outlines the research carried out with modelling loading of machines in FMS with heuristics.

\section{Table 2}

Modelling loading of machines in FMS with heuristics

\begin{tabular}{|c|c|c|}
\hline Athor & Title & Conclusion \\
\hline Stecke (1983a) & Maximize throughput and machine utilizations & $\begin{array}{l}\text { Need exists to develop efficient heuristic algorithms for } \\
\text { more real life solution }\end{array}$ \\
\hline Stecke \& Talbot (1983) & $\begin{array}{l}\text { Minimize part movements, balancing and unbalancing } \\
\text { of workload }\end{array}$ & $\begin{array}{l}\text { None of the developed heuristics was able meet the need of } \\
\text { all FMS }\end{array}$ \\
\hline Hsu \& De-Matta (1997) & Recognize infeasibility of a loading solution & $\begin{array}{l}\text { Proposed Lagrangian-based heuristics } \\
\text { Need of research to develop better methods }\end{array}$ \\
\hline Shankar \& Tzen (1985) & $\begin{array}{l}\text { Minimize workload \& system unbalance and number } \\
\text { of late jobs }\end{array}$ & Developed heuristic methods \\
\hline Shankar \& Tzen (1985) & $\begin{array}{l}\text { Minimize workload \& system unbalance and number } \\
\text { of late jobs }\end{array}$ & Proposed heuristic and sequential methods \\
\hline Shankar \& Srinivasulu ( 1989) & $\begin{array}{l}\text { Bi-criterion objective of minimizing workload } \\
\text { unbalance and maximizing the throughput }\end{array}$ & $\begin{array}{l}\text { Problem with machine-dependent processing times need to } \\
\text { be solved }\end{array}$ \\
\hline Mukhopadhyay et al. (1992) & Minimize system unbalance & Heuristic approach was proposed \\
\hline Kato et al. (1993) & $\begin{array}{l}\text { Batch formation to minimize total number of required } \\
\text { tools }\end{array}$ & Heuristic approach was proposed \\
\hline Roh \& Kim (1997) & Minimize total tardiness & $\begin{array}{l}\text { Solved with limiting part visit to one machine for entire } \\
\text { processing and outlined need of practical research }\end{array}$ \\
\hline Farkas et al. (1999) & Workload balancing and maximize capacity utilization & Results are demonstrated \\
\hline Rahimifard \& Newman ( 2000) & Elimination of tardy jobs & Evaluated series of computer based experiments \\
\hline Tiwari \& Vidyarthi (2000) & Minimize system unbalance and maximize throughput & GA-based heuristic were proposed for optimal solution \\
\hline Tiwari et al. (2007) & $\begin{array}{l}\text { Minimize system unbalance and maximize } \\
\text { throughput }\end{array}$ & $\begin{array}{l}\text { Genetic algorithm based heuristics were found more } \\
\text { efficient than fixed job sequencing rules }\end{array}$ \\
\hline Mukhopadhyay et al. (1998) & Minimize system imbalance & $\begin{array}{l}\text { Proposed modified insertion scheme } \\
\text { Reported higher computational time }\end{array}$ \\
\hline Basnet (Basnet, 2012) & Minimize system unbalance & $\begin{array}{l}\text { Hybrid GA was presented } \\
\text { Stated the need for better heuristics } \\
\text { Outlined the need of empirical research }\end{array}$ \\
\hline
\end{tabular}

Heuristics was the name of a certain branch of study, not very clearly circumscribed, belonging to logic, or to philosophy or to psychology often outlined, seldom presented in detail. A wide range of heuristics procedures have been developed for different manufacturing strategies. Stecke (1986) stated that for large loading problems, heuristics should be used to find good solutions. The loading problems of FMS excessively depend on efficient heuristics for optimum results. Almost all the researcher during 19832013, felt the need of heuristics development for efficient practically acceptable results because the computational cost and time requirement are very less compared to any other technique (Stecke, 1986). Heuristics has been used by many researchers since 1983 for modelling loading of machines in FMS. Literature review outlines that none of the developed heuristics was able meet the need of all FMS (Stecke, 1983a; Stecke \& Talbot, 1983; Hsu \& De-Matta, 1997; Basnet, 2012), thus the need to have a better heuristics for realistic solution is major literature gap. The heuristics always showed improved results with realistic and practical nature with reduced computational requirements whenever used to solve the machine loading problem.

\subsection{Major findings from the literature review}

Mathematical formulation increases the accuracy of the result on the other hand results in complexity resulting with increased computational requirements. There is a need to develop realistic mathematical model with less computational requirements (Swarnkar \& Tiwari, 2004; Tadeusz, 2004). The computational requirements are major identified issues (Stecke, 1983b). literature also reveals that much of the information is usually suppressed in pure mathematical model (Stecke, 1986) may lead to impractical solution (Co et al., 1990). Thus mathematical modelling also needs to be combined with some other techniques to yield practically acceptable realistic results with reasonable computational requirements. There is a need to develop efficient heuristic algorithms for more real life solution (Stecke, 1983a). Requirement of further extension of research was outlined by all researchers (Chan et al., 2004; 
Nagarjuna et al., 2006; Kumar et al., 2006). A real life solution to machine loading problems of FMS with a new solution methodology is still awaited (Yusof et al., 2012; Biswas \& Mahapatra, 2008; Ponnambalam \& Kiat, 2008; Mandal et al., 2010; Yusof et al., 2011; Yusof, Budiarto, \& Venkat, 2011; Abazari et al., 2012; Petrovic \& Akoz, 2008). Researchers also felt the need of real-time FMS control (Stecke \& Brian, 1995) and to develop planning software that can be actually implemented in real systems (Lee et al., 1997). Ammons et al. (1985) stated that the use of heuristics in model development improves computational efficiency \& effectiveness and provides more optimal solution (Berrada \& Stecke, 1986; Ammons et al., 1985; Dobson \& Nambimadom, 2001). Heuristic based methods are more robust in practicality (Yusof et al., 2011). Infeasibility of results can be controlled by condition check on heuristics (Hsu \& De-Matta, 1997). The major issue for need to further reduce computational requirements was outlined in 1983 (Stecke, 1983b) and is still existing (Mandal et al., 2010; Abazari et al., 2012; Mahmudy et al., 2012; Prakash et al., 2008). Heuristics is found to be most suited. Heuristic reasoning is often based on induction, or on analogy. Heuristics are defined as the set of rules that provides optimal or non-optimal solution to the problem with less computational work (Greene \& Sadowski, 1986). With these research gaps and findings to fulfil the research demand the present paper proposes a heuristics--mathematical meta-model for loading of machines in FMS.

\section{Model presentation}

A hybrid hierarchical-heuristic-mathematical modelling and solution methodology has been developed for the optimum utilization of resources in a FMS. The following notations were used for modelling the loading problem.

\begin{tabular}{|c|c|c|}
\hline \multicolumn{3}{|c|}{ Variables } \\
\hline$J_{i}$ & Job number, with $i$ as job index & $i=1,2, \ldots, I$ \\
\hline$M_{x}$ & Machine number with $x$ as machine index & $x=1,2, \ldots, Z$ \\
\hline$O_{y}$ & Operation number with $y$ as operation index & $y=1,2, \ldots, Y$ \\
\hline $\mathrm{To}_{z}$ & Tool number with $z$ as tool index & $z=1,2, \ldots, Z$ \\
\hline$t$ & Time index & $t=1,2, \ldots, T$ \\
\hline$t_{i x y z}$ & \multicolumn{2}{|c|}{ Time requirement by job " $J_{i}$ " on machine " $M_{x}$ " for operation " $O_{y}$ " with tool "To $o_{z}$ (hrs) } \\
\hline$t_{i x}$ & \multicolumn{2}{|c|}{ Material (Job) handling time for job " $J_{i}$ " on machine " $M_{x} "$ (min) } \\
\hline$C_{x z}$ & \multicolumn{2}{|c|}{ Cost of machining per unit time on machine " $M_{x}$ " with too " $T o_{z}$ " (in Rs/min) } \\
\hline$C_{i x}$ & \multicolumn{2}{|c|}{ Handling (Job) cost for job " $J_{i} "$ on machine " $M_{x}$ " (in Rs/min) } \\
\hline$A v_{z}$ & \multicolumn{2}{|l|}{ Available number of tool type " $T o_{z} "$} \\
\hline$M c_{x}$ & \multicolumn{2}{|l|}{ Tool Magazine capacity of machine " $M_{x} "$} \\
\hline$T A l_{x}$ & \multicolumn{2}{|l|}{ Tools allocated to machine " $M_{x} "$} \\
\hline$T o_{i x y}$ & \multicolumn{2}{|c|}{ Number of tools required for operation " $O_{y}$ " on machine " $M_{x}$ " of job " $J_{i}$ " } \\
\hline
\end{tabular}




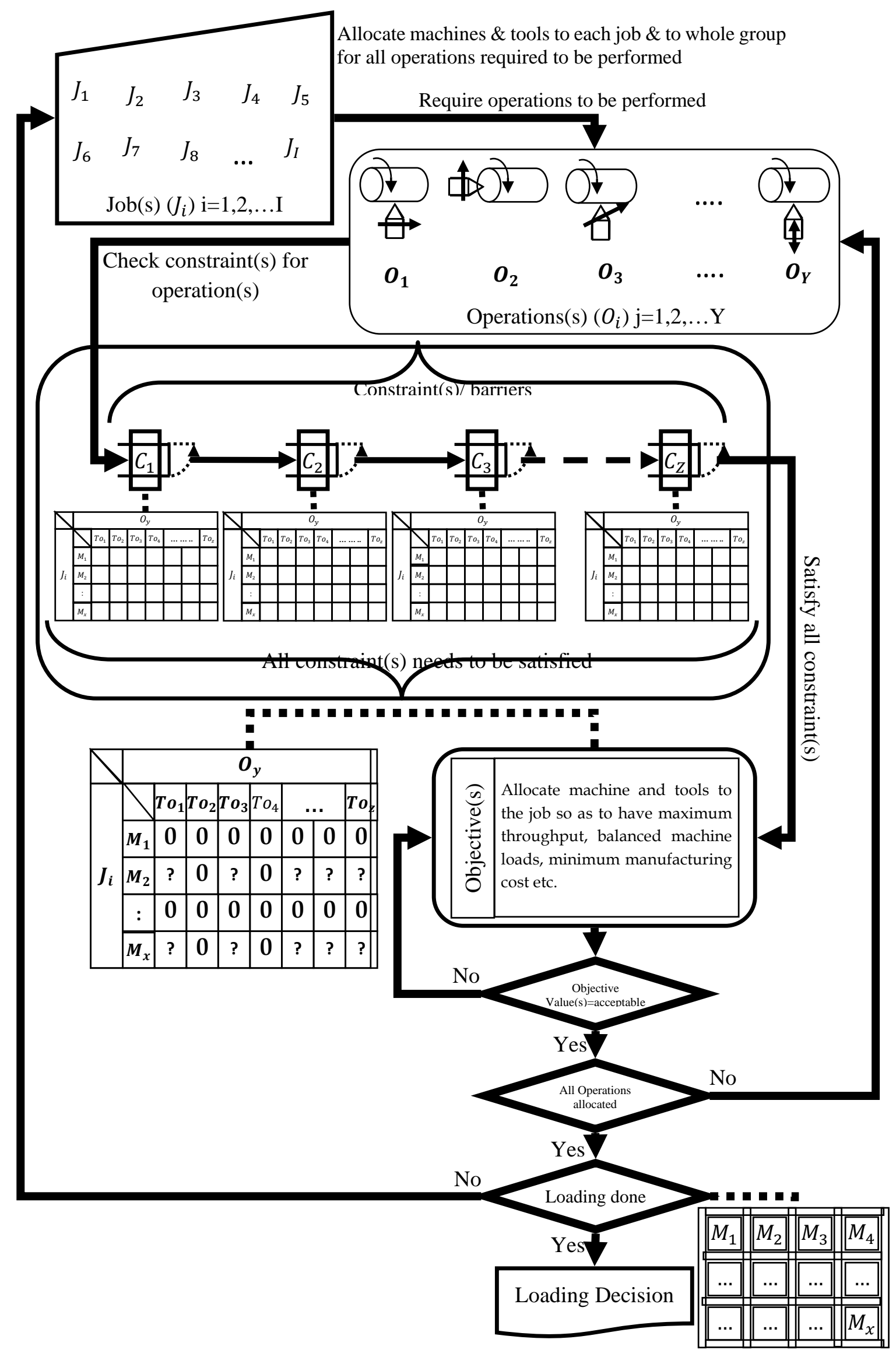

Fig. 1. Diagrammatic representation of the loading problem 
Objective function is $\operatorname{Min}(F)$

where,

$$
F=\operatorname{Min}\left[\operatorname{Min}\left(\sum_{x=1}^{X} \operatorname{Min}\left(f_{1}\right)\right)-\operatorname{Min}\left(f_{2}\right)+\operatorname{Min}\left(f_{3}\right)\right]
$$

where,

$$
\begin{aligned}
& f_{1}=\operatorname{Min}\left(\sum_{i=1}^{I} \sum_{y=1}^{Y} \sum_{z=1}^{Z}\left(t_{i x y z}\right)\left(l_{\text {ixyx }}\right)\right) \\
& f_{2}=\operatorname{Max}\left(\frac{I * X}{\sum_{i=1}^{I} \sum_{x=1}^{X} \sum_{y=1}^{Y} \sum_{z=1}^{Z}\left(t_{i x y z}\right)\left(l_{\text {ixyx }}\right)}\right) \\
& f_{3}=\min \left(\sum_{i=1}^{I} \sum_{y=1}^{Y} \sum_{z=1}^{Z}\left(l_{\text {ixyz }}\right)\left(t_{i x y z}\right)-\sum_{i=1}^{I} \sum_{y=1}^{Y} \sum_{z=1}^{Z}\left(l_{i(\boldsymbol{x}+\mathbf{1}) \boldsymbol{y z}}\right)\left(t_{i(x+1) y z}\right)\right) \approx 0 \quad \forall \boldsymbol{M}_{\boldsymbol{x}}, x \\
&=1,2,(X-1)
\end{aligned}
$$

Decision variables and constraints

$$
\begin{aligned}
& \sum_{y=1}^{Y} \sum_{x=1}^{X} \sum_{z=1}^{Z}\left(l_{i x y z}\right)=\sum_{y=1}^{Y} \sum_{x=1}^{X}\left(M_{i x y}\right)\left(T o_{i x y}\right) \forall \boldsymbol{o}_{y} \text { of } \boldsymbol{J}_{i} \text { and } i, i=1,2,, I \& y=1,2,, Y \\
& \sum_{x=1}^{X} \sum_{z=1}^{Z} l_{i x y z}=\sum_{x=1}^{x}\left(M_{i x y}\right)\left(T o_{i x y}\right) \quad \forall \boldsymbol{o}_{y} \& \boldsymbol{J}_{\boldsymbol{i}}, \quad i=1,2,, I \& y=1,2,, Y \\
& \sum_{x=1}^{X}\left(M_{i x y}\right)=1 \quad \forall \boldsymbol{o}_{\boldsymbol{y}} \text { of } \boldsymbol{J}_{\boldsymbol{i}} \text {, and } i, \quad i=1,2,, I \& y=1,2,, Y \\
& M_{x y}=\left\{\begin{array}{l}
1 \text { if machine } \boldsymbol{M}_{x} \text { can perform operation } \boldsymbol{O}_{\boldsymbol{y}} \\
0 \text { otherwise }
\end{array}\right\} \\
& M_{x y}=\left\{\begin{array}{l}
1 \text { if }\left[\left(\sum_{i=1}^{I} \sum_{y=1}^{Y} \sum_{z=1}^{Z} l_{\text {ixyz }}\right)+T o_{\text {ixy }}\right] \leq \boldsymbol{M} \boldsymbol{c}_{\boldsymbol{x}} \forall \boldsymbol{M}_{\boldsymbol{x}} \\
0 \text { otherwise }
\end{array}\right\} \\
& M_{i x y}=\left\{\begin{array}{l}
1 \text { if tool transportation }(l=1) \text { is allowed } \\
0 \text { otherwise }
\end{array}\right\} \\
& T o_{y z}=\left\{\begin{array}{l}
1 \text { if machine } \boldsymbol{M}_{\boldsymbol{x}} \text { can perform operation } \boldsymbol{O}_{\boldsymbol{y}} \text { with tool } \boldsymbol{T o}_{z} \\
0 \text { otherwise }
\end{array}\right\} \\
& T o_{y z}=\left\{\begin{array}{l}
\left.1 \text { if }\left[\left(\sum_{i=1}^{I} \sum_{x=1}^{X} \sum_{y=1}^{Y} l_{\text {ixyz }}\right)\right] \leq \boldsymbol{A} \boldsymbol{v}_{\mathbf{z}} \forall \boldsymbol{T} \boldsymbol{o}_{\mathbf{z}}\right\} \\
0 \text { otherwise }
\end{array}\right. \\
& l=\left\{\begin{array}{l}
1 \text { if new tool can be buyed } \\
0 \text { otherwise }
\end{array}\right\} \\
& l_{\text {ixyz }}=\left\{\begin{array}{c}
1 \text { if job } \boldsymbol{J}_{\boldsymbol{i}} \text { is loaded on machine } \boldsymbol{M}_{\boldsymbol{x}} \text { for operation } \boldsymbol{O}_{\boldsymbol{y}} \text { with tool } \boldsymbol{T o}_{z} \\
0 \text { otherwise }
\end{array}\right\} \\
& M_{i x y}=\left\{\begin{array}{l}
1 \text { if machine } \boldsymbol{M}_{\boldsymbol{x}} \text { is allocated for operation } \boldsymbol{O}_{\boldsymbol{y}} \text { on job } \boldsymbol{J}_{\boldsymbol{i}} \\
0 \text { otherwise }
\end{array}\right\} \\
& M_{i x}=\left\{\begin{array}{l}
1 \text { if machine } \boldsymbol{M}_{\boldsymbol{x}} \text { is allocated to job } \boldsymbol{J}_{\boldsymbol{i}} \text { for any operation } \\
0 \text { otherwise }
\end{array}\right\} \\
& T o_{i z}=\left\{\begin{array}{l}
1 \text { if tool } \boldsymbol{T o}_{\mathbf{z}} \text { is allocated to job } \boldsymbol{J}_{\boldsymbol{i}} \\
0 \text { otherwise }
\end{array}\right\} \\
& T o_{y z}=\left\{\begin{array}{l}
1 \text { if tool } \boldsymbol{T o}_{z} \text { is allocated for operation } \boldsymbol{O}_{y} \\
0 \text { otherwise }
\end{array}\right\}
\end{aligned}
$$




$$
\begin{aligned}
& J O_{i y}=\left\{\begin{array}{l}
1 \text { if job } \boldsymbol{J}_{\boldsymbol{i}} \text { requires operation } \boldsymbol{O}_{\boldsymbol{y}} \text { to be performed } \\
0 \text { otherwise }
\end{array}\right\} \\
& M O_{x y}=\left\{\begin{array}{l}
1 \text { if Machine } \boldsymbol{M}_{\boldsymbol{x}} \text { can perform operation } \boldsymbol{O}_{\boldsymbol{y}} \\
0 \text { otherwise }
\end{array}\right\} \\
& \text { OTo } o_{y z}=\left\{\begin{array}{l}
1 \text { if operation } \boldsymbol{O}_{\boldsymbol{y}} \text { can be performed by tool } \boldsymbol{T o}_{\mathbf{z}} \\
0 \text { otherwise }
\end{array}\right\} \\
& e_{i y}=\left\{\begin{array}{l}
1 \text { if operation } \boldsymbol{O}_{\boldsymbol{y}} \text { is essential type for joi } J_{i} \\
0 \text { otherwise }
\end{array}\right\} \\
& \operatorname{Tr}=\left\{\begin{array}{l}
1 \text { if tool travel is permitted } \\
0 \text { otherwise }
\end{array}\right\} \\
& j_{s}=\left\{\begin{array}{l}
1 \text { if job is spiliting } \\
0 \text { otherwise }
\end{array}\right\} \\
& j_{a}=\left\{\begin{array}{l}
1 \text { if job is allocated } \\
0 \text { otherwise }
\end{array}\right\} \\
& T M C_{x}=\left\{\begin{array}{l}
1 \text { if tool magazine of machine } M(x) \text { if full } \\
0 \text { otherwise }
\end{array}\right\} \\
& T o A v_{z}=\left\{\begin{array}{l}
1 \text { if tool of type To(z)is available } \\
0 \text { otherwise }
\end{array}\right\} \\
& T o_{b}=\left\{\begin{array}{l}
1 \text { if new tool can be buyed } \\
0 \text { otherwise }
\end{array}\right\} \\
& T o S_{i y z}=\left\{\begin{array}{l}
1 \text { if } j o b \boldsymbol{T o}_{z} \text { is specified for operation } \boldsymbol{O}_{\boldsymbol{y}} \text { to be performed on Job J(i) } \\
0 \text { otherwise }
\end{array}\right\} \\
& y_{i y z}=\left\{\begin{array}{l}
1 \text { if job } \boldsymbol{T o}_{z} \text { is specified for operation } \boldsymbol{O}_{\boldsymbol{y}} \text { to be performed on Job J(i) } \\
0 \text { otherwise }
\end{array}\right\}
\end{aligned}
$$

\section{Heusitics procedure}

As shown from Fig. 2, the following steps are followed:

Step-1 :Allocate all essential operations

Step-2 :Evaluate the differences $\left(\operatorname{Max}\left(t_{x z}\right)\right)$ - $\left(\operatorname{Min}\left(t_{x z}\right)\right)$ between maximum $\left(\operatorname{Min}\left(t_{x z}\right)\right)$ and minimum $\left(\min \left(t_{x z}\right)\right)$ time required by the job $\left(J_{i}\right)$ for an operation $\left(O_{y}\right)$ considering all machines and tools in the system, for all jobs $(i=1,2,3, \ldots, I))$ and operations $(y=1,2,3, \ldots, Y)$ for optional operations only

Step-3 :Select $1^{\text {st }}$ maximum time difference $\left[\operatorname{Max}\left(\left(\operatorname{Max}\left(t_{x z}\right)\right)-\left(\operatorname{Min}\left(t_{x z}\right)\right)\right)\right]$, evaluated in step 2

Step-4 :Allocate optional operation corresponding to the selected time on the machine with least processing time

Step-5 :Put the machine out of selection which reaches above the ideal allocation time

Step-6 :Repeat step 3 for next maximum time difference $\left[\operatorname{Max}\left(\left(\operatorname{Max}\left(t_{x z}\right)\right)-\left(\operatorname{Min}\left(t_{x z}\right)\right)\right)\right]$ in the order of descending processing times till all operations are allocated

Step-7 :Allocation completed

Step-8 :Analyse the values of objectives

Step-9 :Select the $1^{\text {st }}$ objective need to be modified say cost

Step-10:Provide value of cost that needed to be reduced

Step-11:Evaluate the differences $\left(\operatorname{Max}\left(c_{x z}\right)\right)$ - $\left(\operatorname{Min}\left(c_{x z}\right)\right)$ between maximum $\left(\operatorname{Min}\left(c_{x z}\right)\right)$ and minimum $\left(\min \left(c_{x z}\right)\right)$ cost required by the job $\left(U_{i}\right)$ for an operation $\left(O_{y}\right)$ considering all machines and tools in the system, for all jobs $(i=1,2,3, \ldots, I))$ and operations $(y=1,2,3, \ldots, Y)$ for optional operations only

Step-12:Select $1^{\text {st }}$ maximum time cost difference $\left[\operatorname{Max}\left(\left(\operatorname{Max}\left(t_{x z}\right)\right)-\left(\operatorname{Min}\left(t_{x z}\right)\right)\right)\right]$, evaluated in step 11

Step-13: Allocate optional operation corresponding to the selected cost on the machine with least cost

Step-14: Put the machine out of selection which reaches above the ideal allocation value

Step-14: Calculate cost reduction achieved by calculating cost differences between previous and current cost of manufacturing 
Step-15: Repeat step 11 for next operation in the order of descending processing times till the desired cost cutting is achieved

Step-16: Allocation completed

Step-17: Analyse the values of objectives

Step-18: Repeat steps 10 to 17 to put any constraint or limitations or any number of objectives

Step-19: when objective values are acceptable, balance the workload on all machines, i.e. all machines when considered to be available for $24 \times 7$, the entire machines $(\times)$ should run for equal time for optimized loading schedule

Step-20: Select the machine with undesired load, if available shift the tool saving the desired cost/ time

Step-21: Repeat step 20 for all undesired loadings, either saving machining cost at the cost of increased machining time or saving machining time at the cost of increased machining cost.

\section{Results}

Test results of a problem with $\mathrm{I}=5, \mathrm{X}=2, \mathrm{Y}=3, \mathrm{Z}=4$ are discussed below for validation of the proposed model and solution methodology. From the table, ideal value of throughput is 0.02 , balanced load on the system is 249.5 hours load per machine operating at $100 \%$ availability. Here all the operations are considered as optional, with scope of tool travel. The jobs are ordered in sequence of their due dates. All machines are capable of performing all operations, all tools can be loaded on any of the machine. All the jobs can be handled on any of the machines. The results are within known limits of optimal value of optimization, thus are acceptable as per literature guidelines. Thus the developed system is most realistic with least computational requirements best known in the literature.

Table 1

Processing times of various jobs on various machines with different tools for all operations

\begin{tabular}{cccccccccccccc}
\hline & \multicolumn{1}{c}{$\mathrm{O}_{1}$} & \multicolumn{1}{c}{$\mathrm{O}_{2}$} & \multicolumn{3}{c}{$\mathrm{O}_{3}$} \\
& & $\mathrm{To}_{1}$ & $\mathrm{To}_{2}$ & $\mathrm{To}_{3}$ & $\mathrm{To}_{4}$ & $\mathrm{To}_{1}$ & $\mathrm{To}_{2}$ & $\mathrm{To}_{3}$ & $\mathrm{To}_{4}$ & $\mathrm{To}_{1}$ & $\mathrm{To}_{2}$ & $\mathrm{To}_{3}$ & $\mathrm{To}_{4}$ \\
\hline$J_{1}$ & $M_{1}$ & 36 & 6 & 182 & 166 & 137 & 28 & 19 & 103 & 69 & 158 & 22 & 162 \\
& $M_{2}$ & 81 & 171 & 24 & 21 & 95 & 43 & 63 & 154 & 60 & 59 & 26 & 191 \\
\hline$J_{2}$ & $M_{1}$ & 28 & 113 & 200 & 36 & 185 & 181 & 93 & 128 & 151 & 140 & 112 & 139 \\
& $M_{2}$ & 7 & 173 & 110 & 73 & 22 & 15 & 21 & 19 & 3 & 113 & 99 & 27 \\
\hline$J_{3}$ & $M_{1}$ & 190 & 71 & 143 & 12 & 151 & 49 & 202 & 17 & 10 & 81 & 180 & 146 \\
& $M_{2}$ & 61 & 91 & 202 & 106 & 149 & 11 & 68 & 158 & 135 & 13 & 162 & 23 \\
\hline$J_{4}$ & $M_{1}$ & 60 & 11 & 59 & 68 & 114 & 90 & 61 & 183 & 122 & 158 & 149 & 24 \\
& $M_{2}$ & 68 & 36 & 84 & 36 & 38 & 3 & 13 & 108 & 107 & 69 & 11 & 130 \\
\hline$J_{5}$ & $M_{1}$ & 95 & 134 & 94 & 43 & 121 & 182 & 61 & 23 & 148 & 123 & 15 & 67 \\
& $M_{2}$ & 131 & 67 & 155 & 183 & 61 & 40 & 10 & 167 & 143 & 150 & 18 & 133 \\
\hline
\end{tabular}

Table 2

Loading of machines in FMS

\begin{tabular}{|c|c|c|c|c|c|c|c|c|c|c|c|c|c|}
\hline & \multicolumn{4}{|c|}{$O_{1}$} & \multicolumn{4}{|c|}{$\mathrm{O}_{2}$} & \multicolumn{4}{|c|}{$\mathrm{O}_{3}$} \\
\hline & & $T o_{1}$ & $\mathrm{To}_{2}$ & $\mathrm{To}_{3}$ & $\mathrm{To}_{4}$ & $T o_{1}$ & $\mathrm{To}_{2}$ & $T o_{3}$ & $\mathrm{To}_{4}$ & $T o_{1}$ & $\mathrm{To}_{2}$ & $\mathrm{To}_{3}$ & $\mathrm{To}_{4}$ \\
\hline \multirow[t]{2}{*}{$J_{1}$} & $M_{1}$ & 0 & 0 & 0 & 0 & 0 & 0 & 0 & 0 & 0 & 0 & 0 & 0 \\
\hline & $M_{2}$ & 0 & 0 & 0 & 1 & 0 & 1 & 0 & 0 & 0 & 0 & 1 & 0 \\
\hline \multirow[t]{2}{*}{$J_{2}$} & $M_{1}$ & 0 & 0 & 0 & 0 & 0 & 0 & 0 & 0 & 0 & 0 & 1 & 0 \\
\hline & $M_{2}$ & 1 & 0 & 0 & 0 & 0 & 1 & 0 & 0 & 0 & 0 & 0 & 0 \\
\hline \multirow[t]{2}{*}{$J_{3}$} & $M_{1}$ & 0 & 0 & 0 & 0 & 0 & 0 & 0 & 1 & 1 & 0 & 0 & 0 \\
\hline & $M_{2}$ & 1 & 0 & 0 & 0 & 0 & 0 & 0 & 0 & 0 & 0 & 0 & 0 \\
\hline \multirow[t]{2}{*}{$J_{4}$} & $M_{1}$ & 0 & 1 & 0 & 0 & 0 & 0 & 1 & 0 & 0 & 0 & 0 & 0 \\
\hline & $M_{2}$ & 0 & 0 & 0 & 0 & 0 & 0 & 0 & 0 & 0 & 0 & 1 & 0 \\
\hline \multirow[t]{2}{*}{$J_{5}$} & $M_{1}$ & 0 & 0 & 0 & 0 & 0 & 0 & 0 & 1 & 0 & 0 & 1 & 0 \\
\hline & $M_{2}$ & 0 & 1 & 0 & 0 & 0 & 0 & 0 & 0 & 0 & 0 & 0 & 0 \\
\hline
\end{tabular}




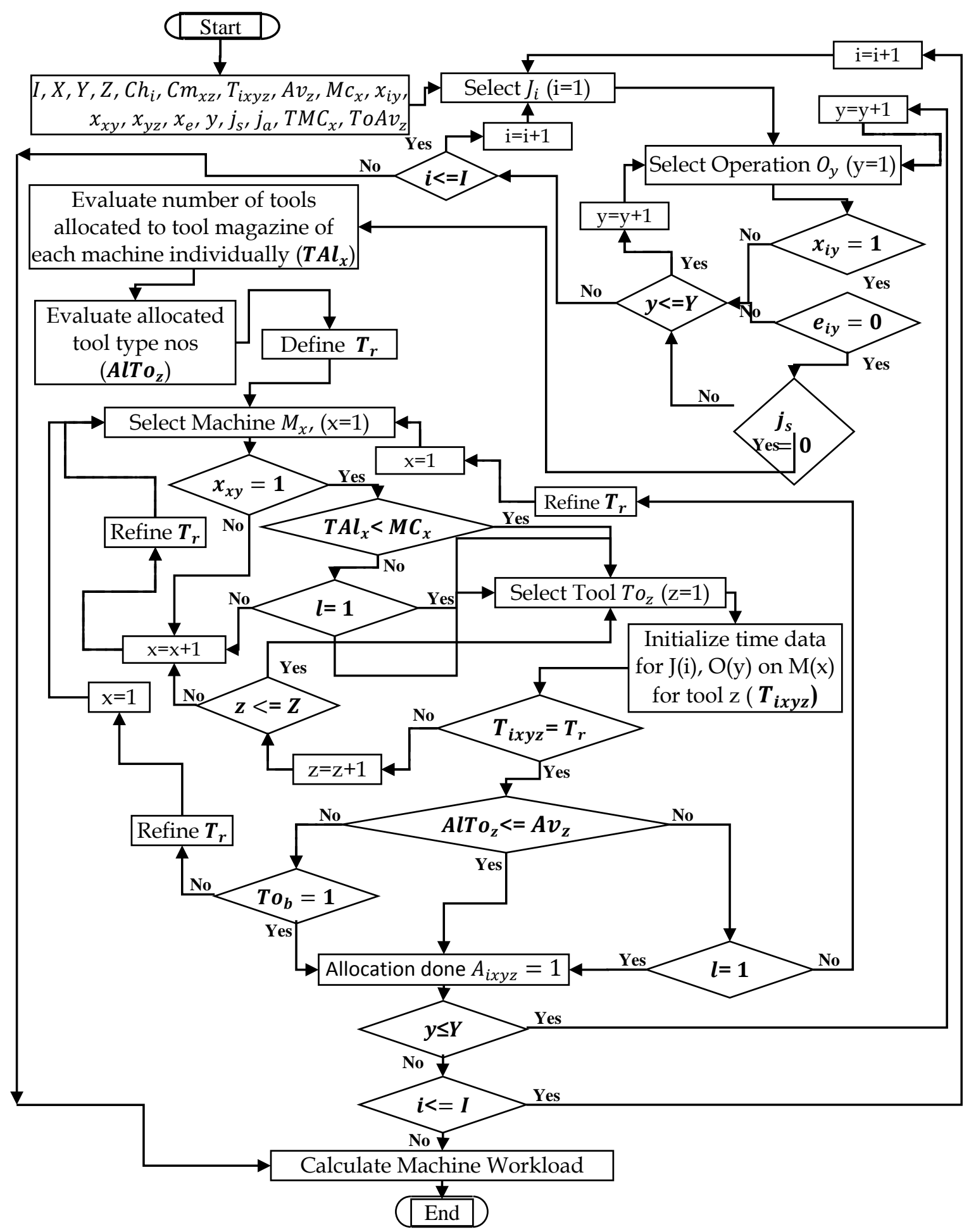

Fig. 2. Developed intelligent algorithm LOMFNEO for allocation of machines and tools for non-essential operations in general FMS

Table 2

Results value

\begin{tabular}{|c|c|c|}
\hline & Load/ Machine & Throughput \\
\hline Ideal value & 249.5 & 0.0200 \\
\hline Actual value & 249 & 249 \\
\hline
\end{tabular}




\section{Conclusion}

Literature also reveals that validation of the a methodology can be accomplished with computationally randomly generated small set of test problems (Sujono \& Lashkari, 2007; Yang \& Wu, 2002; Gamila \& Motavalli, 2003; Chan et al., 2004; Murat \& Erol, 2012; Rahimifard \& Newman, 2000; Yeong-Dae \& Yano Candace, 1987; Rai et al., 2002). The results of this paper have shown that the on solving the proposed model by developed Matlab codes, yields results very close to the ideal values. For example the ideal and actual throughput through proposed modelling when solved with Matlab codes are nearly similar with negligible percentage difference, which are very real world and acceptable results. Also it is outlined in the literature that the solution are feasible within a known percentage of optimal objective value (Bretthauer \& Venkataramanan, 1990).

\section{References}

Abazari, A. M., Solimanpur, M., \& Sattari, H. (2012). Optimum loading of machines in a flexible manufacturing system using a mixed-integer linear mathematical programming model and genetic algorithm. Computers \& Industrial Engineering, 62(2), 469-478.

Ammons, J. C., Lofgren, C. B., \& McGinnis, L. F. (1985). A large scale machine loading problem in flexible assembly. Annals of Operations Research, 3, 319 - 332.

Atmaca, E., \& Erol, S. (2000). Goal programming model for loading and routing problems in flexible manufacturing systems. ICMIT 2000 (IEEE), 843-847.

Basnet, C. (2012). A hybrid genetic algorithm for a loading problem in flexible manufacturing systems. International Journal of Production Research, 50(3), 707-718.

Berrada, M., \& Stecke, K. E. (1986). A branch and bound approach for machine load balancing in Flexible Manufacturing Systems. Management Science, 32(10), 1316-1335.

Bilgin, S., \& Azizoglu, M. (2006). Capacity and tool allocation problem in flexible manufacturing systems. Journal of the Operational Research Society, 57(6), 670-681.

Biswas, S., \& Mahapatra, S. S. (2007). Machine Loading in Flexible Manufacturing System : A Swarm Optimization Approach. In Eighth International Conference on Operations \& Quant. Management ( October 17-20, 2007) (pp. 621-628).

Biswas, S., \& Mahapatra, S. S. (2008). Modified particle swarm optimization for solving machineloading problems in flexible manufacturing systems. International Journal of Advanced Manufacturing Technology, 39, 931-942.

Bretthauer, K. M., \& Venkataramanan, M. A. (1990). Machine loading and alternate routing in a flexible manufacturing system. Computers and Industrial Engineering, 18(3), 341-350.

Chan, F. T. S., Swamkar, R., \& Tiwari, M. K. (2004). A random search approach to the machine loading problem of an FMS. In Proceedings of the 2004 IEEE, Intemational Symposium on Intelligent Control (pp. 96-101). Taipei, Taiwan, September 2-4,2004.

Chen, J., \& Ho, S. (2005). A novel approach to production planning of flexible manufacturing systems using an efficient multi-objective genetic algorithm. International Journal of Machine Tools \& Manufacture, 45, 949-957.

Co, H. C., Biermann, J. S., \& Chen, S. K. (1990). A methodical approach to the flexible manufacturing system batching, loading and tool configuration problems. International Journal of Production Research, 28(12), 2171-2186.

Dobson, G., \& Nambimadom, R. S. (2001). The batch loading and scheduling problem. Operations Research, 49(1), 52-65.

Farkas, A., Koltai, T., \& Stecke, K. E. (1999). Workload Balancing Using the Concept of Operation Types. doi:10.2139/ssrn.160288

Gamila, M. A., \& Motavalli, S. (2003). A modeling technique for loading and scheduling problems in FMS. Robotics and Computer Integrated Manufacturing, 19, 45-54.

Goswami, M., \& Tiwari, M. K. (2006). A reallocation-based heuristic to solve a machine loading problem with material handling constraint in a flexible manufacturing system. International Journal of Production Research, 44(3), 569-588. 
Greene, T. J., \& Sadowski, R. P. (1986). A mixed integer programming for loading and scheduling multiple manufacturing cells. European Journal of Operation Research, 24(3), 379-386. =

Hsu, V. N., \& De-Matta, R. (1997). An efficient heuristic approach to recognize the infeasibility of a loading problem. The International Journal of Flexible Manufacturing Systems, 9, 31-50.

Jahromi, M. H. M. A., \& Tavakkoli-Moghaddam, R. (2012). A novel 0-1 linear integer programming model for dynamic machine-tool selection and operation allocation in a flexible manufacturing system. Journal of Manufacturing Systems, 31(2), 224-231. doi:10.1016/j.jmsy.2011.07.008

Kato, K., Oba, F., \& Hashimot, F. (1993). A GT-based heuristic approach for machine loading and batch formation in flexible manufacturing systems. Control Engineering Practice, 1(5), 845-850.

Kim, H., Yu, J., Kim, J., Doh, H.-H., Lee, D.-H., \& Nam, S.-H. (2012). Loading algorithms for flexible manufacturing systems with partially grouped unrelated machines and additional tooling constraints. International Journal of Advanced Manufacturing Technology, 58, 683-691.

Kim Yeong-Dae and Yano Candace A. (1987). A branch and bound approach for the loading problem in flexible manufacturing systems: an unbalancing case (No. Technical Report 87-18). Ann Arbor, Michigan.

Kosucuoglu, D., \& Bilge, U. (2012). Material handling considerations in the FMS loading problem with full routing flexibility. International Journal of Production Research, 50(22), 6530-6552.

Kouvelis, P., \& Lee, H. L. (1991). Block angular structures and the loading problem in flexible manufacturing systems. Institute for Operations Research and the Management Sciences (INFORMS), 39(4), 666-676.

Kumar, A., Prakash, Tiwari, M. K., Shankar, R., \& Baveja, A. (2006). Solving machine-loading problem of a flexible manufacturing system with constraint-based genetic algorithm. European Journal of Operational Research, 175, 1043-1069.

Kumar, N., \& Shanker, K. (2000). A genetic algorithm for FMS part type selection and machine loading. International Journal of Production Research, 38(16), 3861-3887.

Kumar, N., \& Shanker, K. (2001). Comparing the effectiveness of workload balancing objectives in FMS loading. International Journal of Production Research, 39(5), 843-871.

Kumar, P., Singh, N., \& Tewari, N. K. (1991). A nonlinear goal programming model for multistage, multiobjective decission problems with application to grouping and loding problems in a flexible manufacturing system. European Journal of Operational Research, 53, 166-171.

Kumar, V. M., Murthy, A. N. N., \& Chandrashekara, K. (2012). A hybrid algorithm optimization approach for machine loading problem in flexible manufacturing system. Journal of Industrial Engineering International, 8(3), 1-10.

Lee, D.-H., \& Kim, Y.-D. (1998). Iterative procedures for multi-period order selection and loading problems in flexible manufacturing systems. International Journal of Production Research, 36(10), 2653-2668.

Lee, D.-H., \& Kim, Y.-D. (2000). Loading algorithms for flexible manufacturing systems with partially grouped machines. IIE Transactions, 32, 33-47.

Lee, D.-H., Lira, S.-K., Lee, G.-C., Jun, H.-B., \& Kim, Y.-D. (1997). Multi-period part selection and loading problems in flexible manufacturing systems. Computers and Industrial Engineering, 33(3-4), 541-544.

Mahmudy, W. F., Marian, R. M., \& Luong, L. H. S. (2012). Solving part type selection and loading problem in flexible manufacturing system using real coded genetic algorithms - Part II : optimization. World Academy of Science, Engineering and Technology, 69, 778-782.

Mandal, S. K., Pandey, M. K., \& Tiwari, M. K. (2010). Incorporating dynamism in traditional machine loading problem : an AI-based optimisation approach. International Journal of Production Research, 48(12), 3535-3559.

Maria, A. (1997). Introduction to modeling and simulation. In S. Andradottir, K. J. Healy, D. H. Withers, \& B. L. Nelson (Eds.), Proceedings of the 1997 Winter Simulation Conference (pp. 7-13).

Mgwatu, M. I. (2011). Interactive decisions of part selection, machine loading , machining optimisation and part scheduling sub-problems for flexible manufacturing systems. International Transaction Journal of Engineering, Management, \& Applied Sciences \& Technologies, 2(1), 93-109. 
Mukhopadhyay, S. K., Midha, S., \& Murlikrishna, V. (1992). A heuristic procedure for loading problem in flexible manufacturing systems. International Journal of Production Research, 30(9), 2213-2228.

Mukhopadhyay, S. K., Singh, M. K., \& Srivastava, R. (1998). FMS machine loading: A simulated annealing approach. International Journal of Production Research, 36(6), 1529-1547.

Murat, A., \& Erol, S. (2012). A hybrid simulated annealing-tabu search algorithm for the part selection and machine loading problems in flexible manufacturing systems. International Journal of Advanced Manufacturing Technology, 59, 669-679.

Nagarjuna, N., Mahesh, O., \& Rajagopal, K. (2006). A heuristic based on multi-stage programming approach for machine-loading problem in a flexible manufacturing system. Robotics and ComputerIntegrated Manufacturing, 22, 342-352.

Nayak, G. K., \& Acharya, D. (1998). Part type selection, machine loading and part type volume determination problems in FMS planning. International Journal of Production Research, 36(7), 1801-1824.

Ozdamarl, L., \& Barbarosoglu, G. (1999). Hybrid heuristics for the multi-stage capacitated lot sizing and loading problem. Journal of the Operational Research Society, 50(8), 810-825.

Ozpeynirci, S., \& Azizoglu, M. (2010). A Lagrangean relaxation based approach for the in flexible allocation capacity problem manufacturing systems. Journal of the Operational Research Society (20, 61(5), 872-877.

Petrovic, D., \& Akoz, O. (2008). A fuzzy goal programming approach to integrated loading and scheduling of a batch processing machine. Journal of the Operational Research Society, 59(9), 12111219.

Ponnambalam, S. G., \& Kiat, L. S. (2008). Solving machine loading problem in flexible manufacturing systems using particle swarm optimization. World Academy of Science, Engineering and Technology, 2, 14-19.

Prakash, A., Khilwani, N., Tiwari, M. K., \& Cohen, Y. (2008). Modified immune algorithm for job selection and operation allocation problem in flexible manufacturing systems. Advances in Engineering Software, 39, 219-232.

Rahimifard, S., \& Newman, S. T. (2000). Machine loading algorithms for the elimination of tardy jobs in flexible batch machining applications. Journal of Materials Processing Technology, 107, 450-458.

Rai, R., Kameshwaran, S., \& Tiwari, M. K. (2002). Machine-tool selection and operation allocation in FMS: Solving a fuzzy goal-programming model using a genetic algorithm. International Journal of Production Research, 40(3), 641-665.

Rajamani, D., \& Adil, G. K. (1996). Machine loading in flexible manufacturing systems considering routeing flexibility. International Journal of Advanced Manufacturing Technology, 11, 372-380.

Roh H.-K. and Kim Yeon-D. (1997). Due-date based loading and scheduling methods for a flexible manufacturing system with an automatic tool transporter. International Journal of Production Research, 35(11), 2989-3004.

Sarin, S. C., \& Chen, C. S. (1987). The machine loading and tool allocation problem in a flexible manufacturing system. International Journal of Production Research, 25(7), 1981-1094.

Shankar, K., \& Srinivasulu, A. (1989). Some selection methodologies for loading problems in a flexible manufacturing system. International Journal of Production Research, 27(6), 1019-1034.

Shankar, K., \& Tzen, Y. J. (1985). A loading and dispatching problem in a random flexible manufacturing system. International Journal of Production Research, 23(3), 579-595.

Stecke, K. E. (1981). Linearized nonlinear MIP formulation for loading a Flexible Manufacturing System. The University of Michigan, Working Paper No 278.

Stecke, K. E. (1983a). A hierarchical approach to solving machine grouping and loading problems of FMS. The University of Michigan, Working Paper No. 331-C.

Stecke, K. E. (1983b). Formulation and solution of nonlinear integer production planning problems for flexible manufacturing systems. Management Science, 29(3), 273-288.

Stecke, K. E. (1986). A hierarchical approach to solving machine grouping and loading problems of flexible manufacturing systems. European Journal of Operational Research, 24, 369-378. 
Stecke, K. E., \& Brian, T. F. (1995). Heuristics for loading flexible manufacturing systems. In Raouf A. and Ben-Daya M. (Ed.), Flexible manufacturing systems: recent developments (pp. 171-180). Elsevier Science B.V.

Stecke, K. E., \& Talbot, F. B. (1983). Heuristic loading algorithms for Flexible Manufacturing System. The University of Michigan, Working Paper No 348.

Sujono, S., \& Lashkari, R. S. (2007). A multi-objective model of operation allocation and material handling system selection in FMS design. International Journal Production Economics, 105, 116133. doi:10.1016/j.ijpe.2005.07.007

Swarnkar, R., \& Tiwari, M. K. (2004). Modeling machine loading problem of FMSs and its solution methodology using a hybrid tabu search and simulated annealing-based heuristic approach. Robotics and Computer-Integrated Manufacturing, 20, 199-209.

Taboun, S. M., \& Ulger, T. (1992). Multi-objective modelling of operation-allocation problem in flexible manufacturing systems. Computers and Industrial Engineering, 23(1-4), 295-299.

Tadeusz, S. (2004). Loading and scheduling of a flexible assembly system by mixed integer programming. European Journal of Operational Research, 154, 1-19.

Tiwari, M. K., Saha, J., \& Mukhopadhyay, S. K. . (2007). Heuristic solution approaches for combinedjob sequencing and machine loading problem in flexible manufacturing systems. International Journal of Advanced Manufacturing Technology, 31, 716-730.

Tiwari, M. K., \& Vidyarthi, N. K. (2000). Solving machine loading problems in a flexible manufacturing system using a genetic algorithm based heuristic approach. International Journal of Production Research, 38(14), 3357-3384.

Turkcan, A., Akturk, M. S., \& Storer, R. H. (2007). Due date and cost-based FMS loading , scheduling and tool management. International Journal of Production Research, 45(5), 1183-1213.

Ventura, J. A., Frank, C. F., \& Leonard, M. S. (1988). Loading tools to machines in flexible manufacturing systems. Computers \& Industrial Engineering, 15(1-4), 223-230.

Wilson J. M. (1992). Approaches to machine load balancing in flexible manufacturing systems. The Journal of the Operational Research Society, 43(5), 415-423.

Yang, H., \& Wu, Z. (2002). GA-based integrated approach to FMS part type selection and machineloading problem. International Journal of Production Research, 40(16), 4093-4110.

Yaqoub, D. Z. H., \& Abdulghafour, D. A. B. (2012). Development of Job Scheduling and Machine Loading System in FMS. Engineering \& Technology Journal, 30(7), 1173-1186.

Yogeswaran, M., Ponnambalam, S. G., \& Tiwari, M. K. (2009). An efficient hybrid evolutionary heuristic using genetic algorithm and simulated annealing algorithm to solve machine loading problem in FMS. International Journal of Production Research, 47(19), 5421-5448.

Yusof, U. K., Budiarto, R., \& Deris, S. (2011). Harmony search algorithm for flexible manufacturing system ( FMS ) machine loading problem. In 3rd IEEE Conference on Data Mining and Optimization (DMO), 28-29 June 2011 (pp. 26-31). Selangor, Malaysia.

Yusof, U. K., Budiarto, R., \& Deris, S. (2012). Constraint-chromosome genetic algorithm for flexible manufacturing system machine-loading problem. International Journal of Innovative Computing, Information and Control, 8(3), 1591-1609.

Yusof, U. K., Budiarto, R., \& Venkat, I. (2011). Machine loading optimization in flexible manufacturing system using a hybrid of bio-inspired and musical-composition approach. In Sixth International Conference on Bio-Inspired Computing: Theories and Applications (IEEE) (pp. 89-96). 